\title{
Resistance in sorghum to the shoot fly, Atherigona soccata: epicuticular wax and wetness of the central whorl leaf of young seedlings
}

\author{
By K. F. NWANZE, R. J. PRING', P. S. SREE. D. R. BUTLER, \\ Y. V. R. REDDY and P. SOMAN \\ International Crops Research Institute for the Semi-Arid Tropics (ICRISAT). \\ Patancheru, P. O. Andhra Pradesh 502 324. India \\ 'Department of Agricultural Sciences, University of Bristol, AFRC Institute of \\ Arable Crops Research, Long Ashton Research Station, Long Ashton. Bristol \\ BS18 9AF, UK
}

(Accepted 3 February 1992)

\begin{abstract}
Summary
Sorghum genotypes known to be resistant or susceptible to shoot fly. Atherigona soccata Rondani were examined by scanning electron microscopy for differences in epicuticular wax structure and wetness of the central leaf whorl. Two major types of wax structures were observed: shoot fly resistant and moderately resistant genotypes were characterised by a smooth amorphous wax layer and sparse wax crystals while susceptible genotypes possessed a dense meshwork of crystalline epicuticular wax. The density of wax crystals decreased from the third leaf to the seventh leaf stage and was related to both seedling age and leaf position. Water droplets on susceptible genotypes with dense wax crystals showed spreading at the edges indicating a tendency to wet easily. In resistant genotypes with less dense wax crystals the droplets remained intact and did not spread.
\end{abstract}

Key words: Sorghum, seedlings, shoot fly, leaf surface wetness, epicuticular wax structure, resistance

\section{Introduction}

The behaviour and survival of the shoot fly, Atherigona soccata Rondani (Muscidae: Diptera) have been associated with the presence of moisture on sorghum leaves. The first reported studies on this phenomenon (Blum, 1963; Raina, 1981) referred to morning dew or moisture on the expanded leaf on which eggs were laid and from which larvae move towards the central whorl (shoot) leaf of sorghum seedlings. Recent studies by Nwanze, Reddy \& Soman (1990) showed that larvae spend less than 30) min on the leaf where the egg is laid, compared to $>3 \mathrm{~h}$ for larvae to travel from the funnel of the central whorl leaf to the growing point. While initial contact with moisture on the expanded leaf enhances larval movement, speed of movement and survival were affected more by the wetness on the central whorl leaf. Moisture on this leaf is different from dew on expanded leaves or rain water within the whorl, which can easily be dislodged by gentle tapping. Our studies showed differences between the leaf surface wetness (LSW) on shoot fly-resistant and susceptible genotypes and that LSW varied with seedling age (Nwanze et al., 199()). Larvae (C) 1992 Association of Applied Biologists 
moved faster and caused deadhearts more easily in younger than in older seedlings. They also moved faster in susceptible genotypes (with more LSW) than in resistant ones (with less LSW).

Evidence from subsequent studies (Nwanze et al. . 1992) suggest that LSW is not due to condensation of moisture from the atmosphere but originates from the plant. It was also postulated that the different amounts of L.SW on shoot fly-susceptible and resistant genotypes indicate that there are genetic differences between cultivars which govern the rate of supply of'LSW.

The aerial surfaces of all higher plants carry a partial or continuous coverage of amorphous wax. Formations of crystalline epicuticular wax are frequently superimposed upon these amorphous layers and may appear as flakes, rods, plates, filaments or occasional deposits of composites of these (Baker. 1982). Surface wax on leaves is deposited only on young leaves during the period of leaf development and expansion, and is related to the development and solidification of the cuticular layer (Schieferstein \& Loomis, 1956; Hallam, 1970)). (hanges are known to occur in epicuticular wax composition and structure as the leaf ages (Foboya. Okogun \& Goddard, 1980; Atkin \& Hamilton, 1982; Blaker \& (Greyson, 1988).

In the Gramineae, epicuticular waxes have mostly been studied for either phytochemical or commercial reasons in connection with wetting of leaves and the absorption of chemical sprays by plants (Bianchi, Avato, Bertirelli \& Mariani, 1978: Tulloch \& Bergter, 1980); Tulloch \& Hoffman, 1979). However, evaluations of the role of epicuticular waxes in drought resistance in maize (Blum, 1975) and oat (Bengston, Larsson \& Lilijenberg, 1978) and for insect resistance in sorghum (Atkin \& Hamilton, 1982; Taneja \& Woodhead, 1989) have also been reported.

In the present study, we examined the structure of the epicuticular wax of unexpanded leaves of various sorghum genotypes in relation to the presence of surface moisture. We used low temperature scanning electron microscopy (LTSEM) to examine the epicuticular waxes of the central whorl leaves of shoot fly-resistant and susceptible sorghum seedlings at different ages. We also conducted LTSEM examination of the surface moisture on these leaves.

\section{Materials and Methods}

\section{Plant material}

We used seven sorghum genotypes: three shoot fly-resistant (IS 18551, IS 2146 and IS 1057), one moderately resistant (IS 1054) and three susceptible (IS 1046, CSH 1 and CSH 5). Potted plants were grown at Long Ashton Research Station (LARS), UK, in a glasshouse under supplemented natural daylight of $c .350-1100 \mu \mathrm{mol} \mathrm{m}{ }^{\prime} \mathrm{s}$ ' for a $16 \mathrm{~h}$ daylight period. Relative humidity and temperature were maintained at $45-55 \%$ day, $65-75 \%$ night and $28-$ $30^{\circ} \mathrm{C}$ day, $25-28^{\circ} \mathrm{C}$ night, respectively. Plants were watered from the base by an automatic watering system.

For studies on epicuticular wax structure, leaf samples were taken from seedlings of all seven genotypes at the 5 th leaf growth stage, corresponding to $c .12$ days after seedling emergence (DAE). For comparative studies on differences in wax structure with seedling age, seedlings of IS 18551. IS 1054. IS 1046 and CSH 1 at the 3rd, 5th and 7th leaf stages, corresponding respectively to 7,12 and 21 DAE were used.

\section{Scanning electron microscopy}

Studies were carried out at LARS using a Philips 505 SEM interfaced with a Hexland 
cryo system (Oxford Instruments Ltd, Oxford, UK). Leaf samples, c. $5 \mathrm{~mm} \times 5 \mathrm{~mm}$. from the central whorl leaves were unrolled and mounted. adaxial surface uppermost. on a copper specimen holder using a mixture of "Tissue-Tek" (Agar Scientific. Stansted. Essex. UK) and colloidal graphite. Samples were first frozen by placing the specimen holder in contact with a copper block. cooled to -150$)^{\circ} \mathrm{C}$. in the pre-chamber. This departure from "standard" LTSEM cryofixation practice was done to prevent the mechanical disturbance of surface structure or of water droplets by interaction with a turbulent cryogenic liquid. Prior to sputter coating with c. $25 \mathrm{~nm}$ of gold, they were transferred to the cold stage of the SEM and examined at low $\mathrm{kV}(c .2 .5 . \mathrm{kV})$ for contaminating ice crystals which if present, were allowed to sublime by warming to $-711^{\circ} \mathrm{C}$. After sputter coating. samples were then examined at an accelerating voltage of $f-6 \mathrm{kV}$ at a temperature of $-1.30^{\circ} \mathrm{C}$, $\mathrm{c}$ $-150)^{\circ} \mathrm{C}$. Micrographs were recorded using Ilford FP4 or Kodak T-Max 100 film.

In order to visualise surface moisture on the unexpanded central whorl leaf of 5 th keaf stage seedlings, samples of rolled-up leaves (IS 18551. IS 1057. IS 1(1)46 and (SH 1) were mounted on the specimen holder as described above. After freezing and evacuation of the pre-chamber, each sample was fractured with a cold blade in the pre-chamber, thus revealing the surface of the leaf. SEM examination was performed as described earlier.

To confirm differences in the wettability between genotypes, pieces of unrolled central whorl leaves of 5 th leaf stage seedlings of the same four genotypes were used. The exposed surfaces were sprayed with a two second burst of distilled water using a hand-held attomiser and the samples were then immediately frozen by placing them in contact with a cold block at $-175^{\circ} \mathrm{C}$. SEM examinations were performed as described above.

\section{Results}

Variation in w'ax structure between genotypes

Two major types of surface wax were observed. In the shoot fly-susceptible genotypes CSH 1 and CSH 5, leaf surfaces were generally covered with a dense meshwork of erystalline epicuticular wax flakes with occasional alternating regions of dispersed crystals or smooth wax (Fig. 1). In resistant IS 18551 . IS 2146 and IS 1057 , the surfaces were generally characterised by a smooth amorphous wax layer with relatively sparse patches or clusters of wax crystals (Fig. 2). The smooth amorphous wax layer of moderately resistant IS 1054 was more densely interspersed with wax crystals than it was for the resistant genotypes. The susceptible genotype IS 1046 showed a completely different wax structure. At higher magnification, the smooth amorphous wax layer consisted of a fine granular structure (Fig. 3).

\section{Variation in wax structure with seedling age}

The SEM micrographs showed a tendency in all four genotypes for the density of distribution of wax crystals to decrease from the 3rd (7 DAE) to the 7th (21 DAE) leaf stage, although in some cases, the size of the crystals increased. In CSH 1, the dense meshwork of crystalline wax was retained from the 3rd to the 5th leaf stage (12 DAE; Fig. 1), but became very sparse and scattered at the 7th leaf stage, similar to the density of wax crystals on resistant genotypes (Fig. 2). In genotype IS 1(046, the distribution of wax crystals became more sparse from the 3 rd to the 5 th leaf. However, this revealed a very fine granular wax surface which became clearly defined at the 5th leaf stage (Fig. 3). Similarly, both IS 


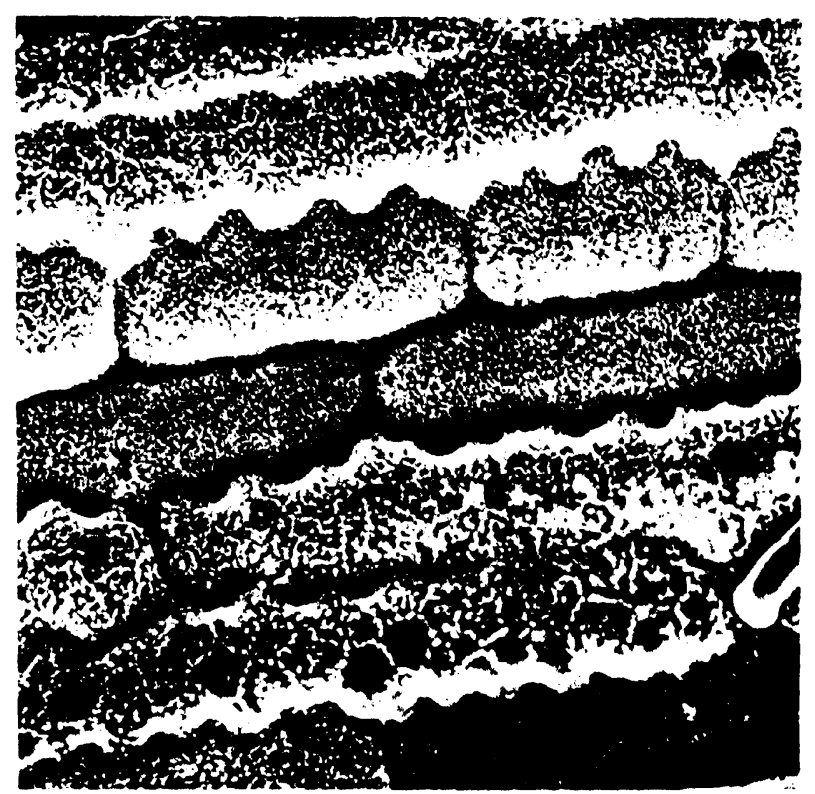

Fig. 1. Dense meshwork of crystalline flakes on shootfly-susceptible CSH 1 at the 5 th leaf stage (12 DAE) (Also typical of CSH 5). $\times 600$

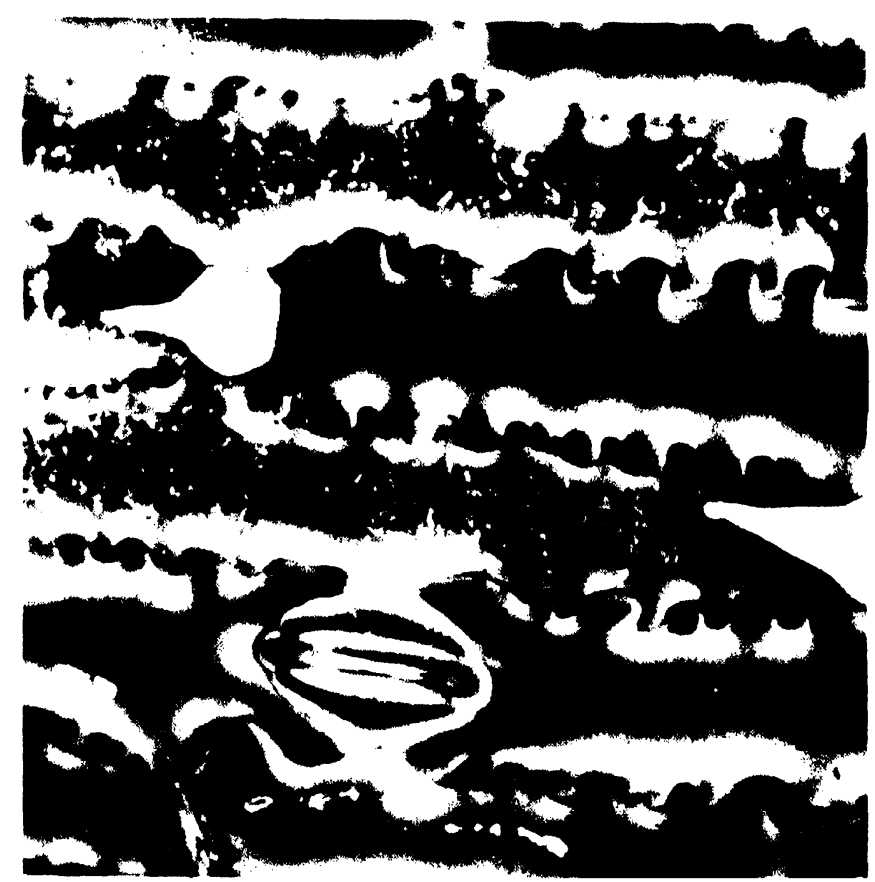

Fig. 2. Smooth amorphous wax surface with sparse crystals on shootfly-resistant genotype IS 18551 at the 5 th leaf stage (12 DAE). (Also typical of IS 18551, IS 1057 and IS 2146). $\times 600$ )

18551 and IS 1054 that were densely covered with scattered wax crystals at the 3rd leaf stage (Fig. 4), were more sparsely covered with wax flakes at the 5th leaf stage (Fig. 2).

\section{SEM of leaf surface wetness}

The naturally occurring moisture on the surfaces of CSH 1 and IS 1046 appeared as large droplets, many of which showed spreading at the edges (Fig. 5). Very small spherical droplets were also present. No droplets were observed in IS 18551 and IS 1057. 

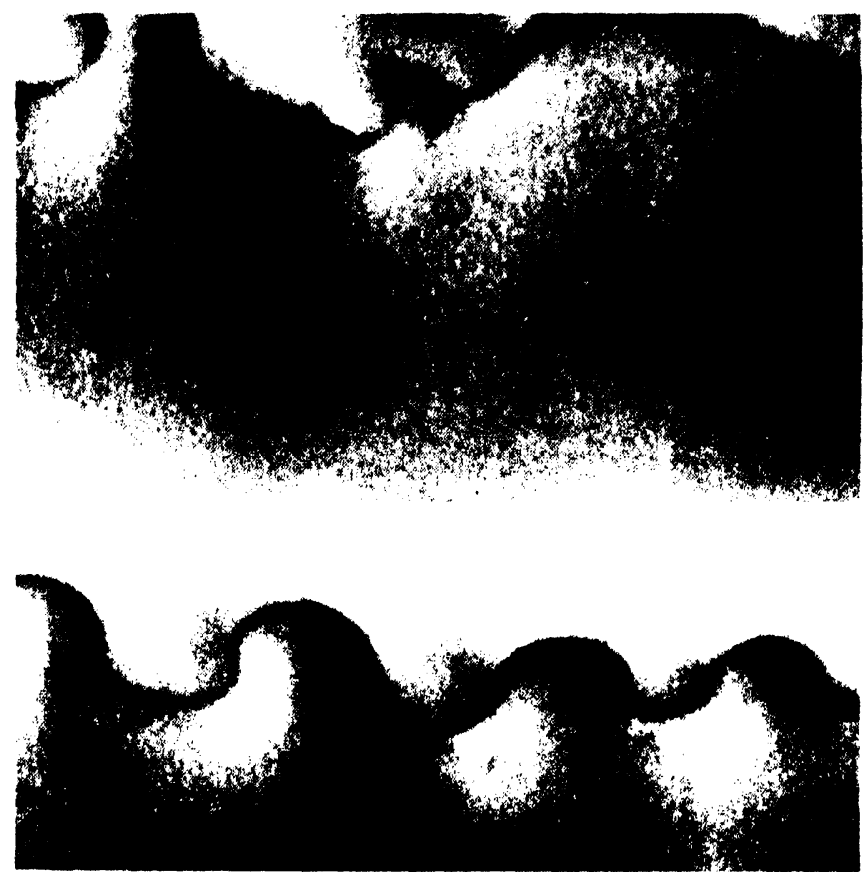

Fig. 3. Fine granular structure of shootfly-susceptible IS 1046 at 5 th leaf stage (12 DAE) at higher magnification. $\times 2400$

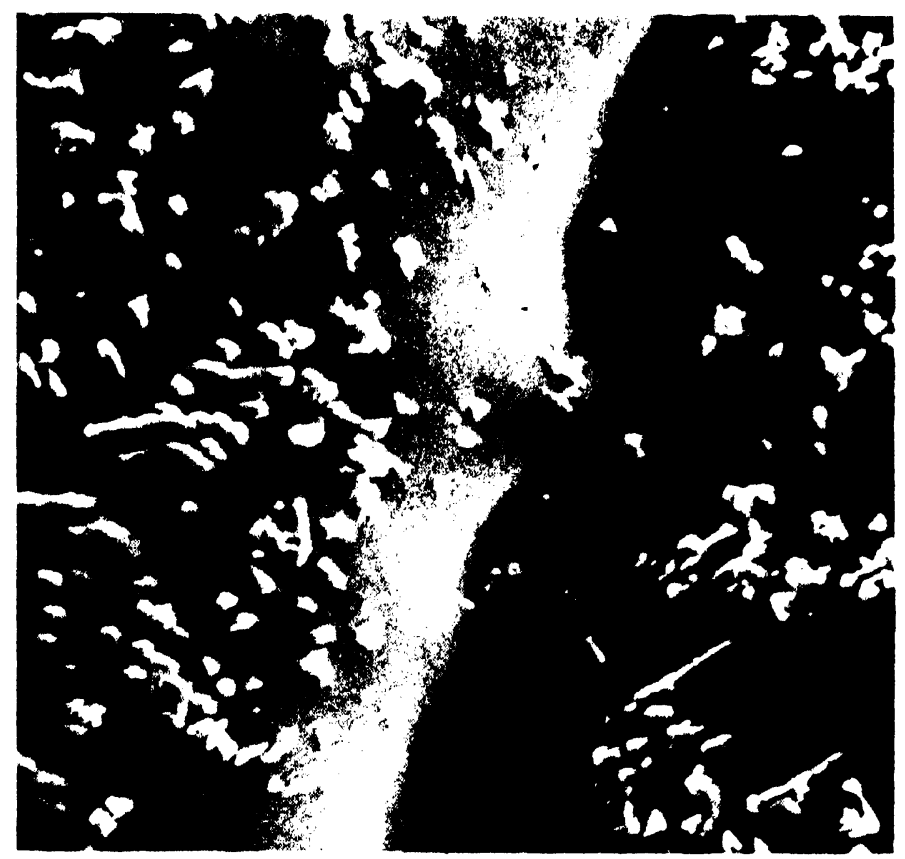

Fig. 4. Variation in wax structure with seedling age. Scattered wax crystals of IS 18551 at 3rd leaf stage (7 DAE). (Also typical of IS 1054$). \times 2400$

Similarly, SEM of artificially wetted leaf surfaces revealed droplets in CSH 1 and IS 1046 that were beginning to spread (Fig. 6) indicating a small contact angle and a tendency to wet, while in genotypes IS 18551 and IS 1057 , the droplets remained more tightly spherical and did not spread (Fig. 7). 


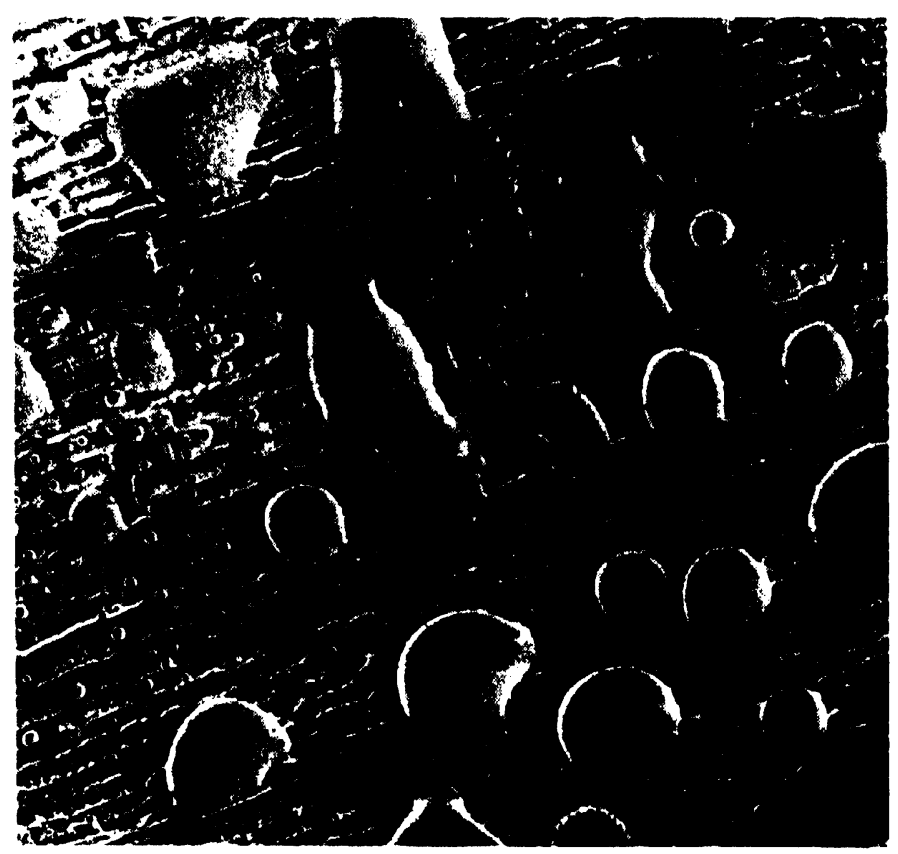

Fig. 5. Large spreading droplets of naturally occurring moisture on CSH 1 at 5th leaf stage (12 DAE). (Also typical of IS 1046). $\times 800$

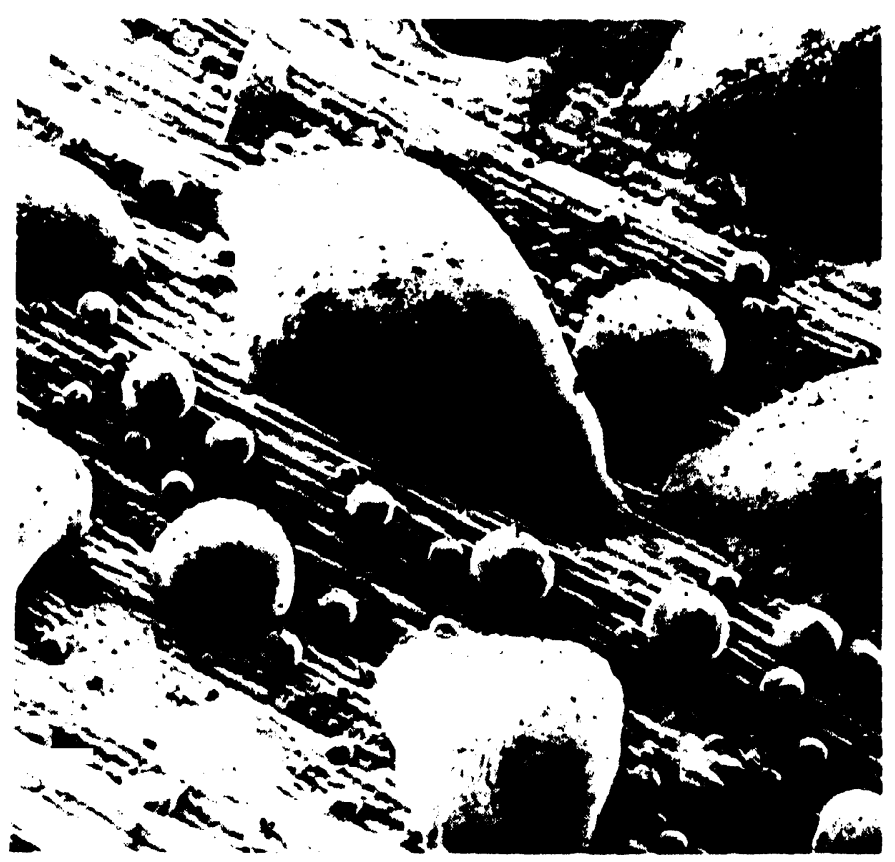

Fig. 6. Large spreading droplets (indicating high wettability) on CSH 1 at 5th leaf stage (12 DAE) sprayed with a $2 \mathrm{~s}$ burst of distilled water. (Also typical of IS 1046). $\times 150$

\section{Discussion}

The range of sorghum genotypes used in these studies enabled us to observe distinct differences in the structure of the epicuticular wax on sorghum leaves. Baker (1982) indicated that wax morphology was under genetic control. We observed two distinct groups at the 5th leaf stage: (a) shoot fly-resistant genotypes with a smooth amorphous wax layer 


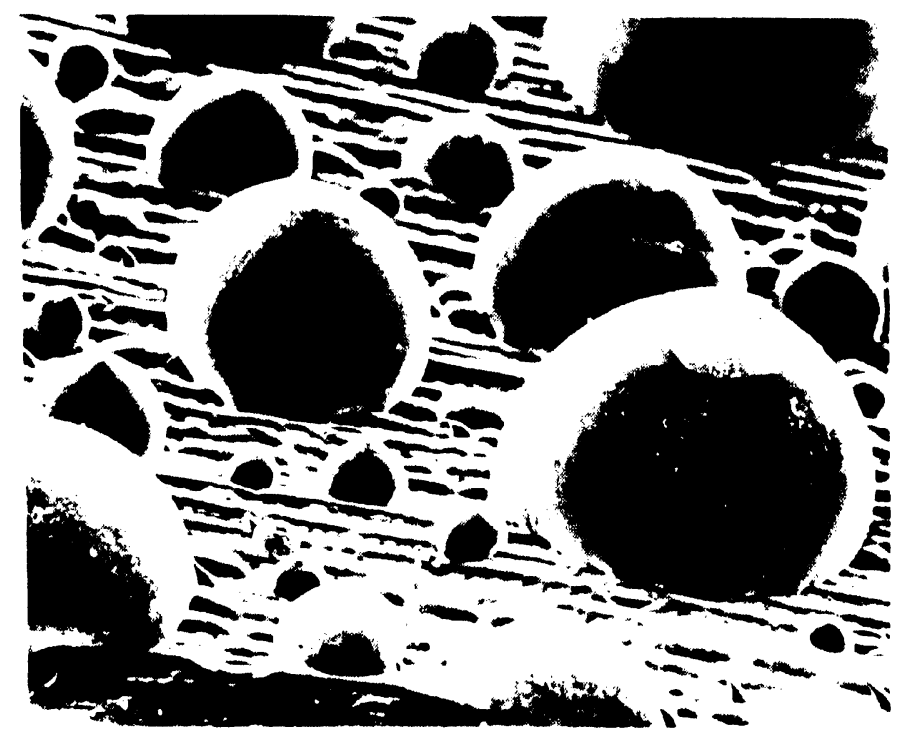

Fig. 7. Almost spherical droplets (indicating low wettability) on IS 18551 at 5th leaf stage (12 DAE) sprayed with a $2 \mathrm{~s}$ burst of distilled water. (Also typical of is 1057 ). $\times 2(0)$

and sparse wax crystals and (b) susceptible genotypes with a dense meshwork of crystalline epicuticular wax. The fine granular structure typical of IS $1(1) 46$ has also been reported in maize (Schieferstein \& Loomis, 1956) where it is known to develop into soft mounds of semicrystalline wax or crusts. Studies by Atkin \& Hamilton (1982) also reported differences in the arrangement of wax flakes on two sorghum genotypes (SH 1 and IS IO82. They also found differences in wax composition. Differences in epicuticular wax morphology are known to indicate differences in chemical composition (Baker, 1982), and although we did not analyse the chemical composition of surface waxes, we infer from our observations on wax structure and from our other studies on amount of surface wax (Sree, 1991) that such differences may exist.

Changes in surface wax deposition (amount, composition and structure) with plant age, have been reported from several plant species (Mueller, Carr \& Loomis, 1954; Schieferstein \& Loomis, 1956; Foboya et al., 1980); Hallam, 1982; Blaker \& (jreyson, 1988). Atkin \& Hamilton (1982) also reported similar changes in sorghum leaves. However, in our studies, the differences in wax structure were not only age-related. Since we were interested in the central whorl leaf, which is the path of newly hatched larvae, we examined this leaf at different seedling growth stages when sorghum is most susceptible to shoot fly infestation. At all age groups examined (7, 12 and 21 DAE), the leaves (respectively 3 rd, 5 th and 7 th) were usually 3-4 days old, calculated from when the tip of the leaf first appeared in the whorl. Thus, we were invariably examining leaves of the same age on seedlings of different ages. Therefore, the differences in wax structure which we observed at different growth stages are related to both seedling age and leaf position. Blaker \& Greyson (1988) also reported similar differences in maize. Our earlier studies indicated that LSW was higher in younger than in older seedlings. This suggests a link between LSW and wax structure.

The wettability of leaves depends on the amount, composition and structure of waxes (Schieferstein \& Loomis, 1956) and contact angles between water and leaf surfaces is a quantitative measure of surface wetting (Linskens, 1951; Fogg, 1947). For a completely wettable surface the contact angle would be zero and for a completely non-wettable surface, the angle would be $180^{\circ}$. Large contact angles are commonly associated with the presence of wax crystals on the leaf surface and small contact angles are found on leaves with a 
smooth amorphous wax surface (Fernandes. 1965), but chemical constituents also affect the wettability (Fernandes, 1965: Holloway. 1969).

Our results indicate that the wettability was greatest with genotypes CSH 1. CSH 5 and IS 1046. These are all shoot fly-susceptible. and CSH 1 and CSH 5 both have crystalline wax deposits on the leaf surface. The resistant genotypes IS 18551. IS 2140 and IS 1057 were generally characterised by a smooth amorphous surface, yet surface water forms tight droplets, indicated low wettability. Contact angles were not measured, but the effect is clear in the micrographs (Fig. 7). It is an unexpected result which differs from other reports of the effect of wax crystals (Fernandes, 1965; Holloway, 1970) and merits further investigation. One possible explanation is that our studies relate to unexpanded leaves whereas previous reports are for expanded leaves, and the various contributions of the complex wax structure (roughness), wax chemistry, composite (air films) and non-composite surfaces affecting wettability may differ considerably between the two situations. Our results call for detailed investigation with expanded and unexpanded leaves of different genotypes where wax chemical composition (which is also known to influence wettability) is analysed and contact angles are measured. Such a detailed study is beyond the seope of this paper.

Observed differences in the amount of LSW could result from differences in the supply of water to the surface, differences in retention, or differences in the evaporation of surface water. Water retention could be less on a water repellent (non-wettable) surface, but it remains to be shown if wax structure relates to the supply of LSW. The degree to which water spreads on the leaf surface will affect the rate that it evaporates; a large surface area for a given volume of water will result in a similarly large evaporation rate. We would expect the ratio of surface area to volume to be smallest with the almost spherical droplets on the water repellant surface (reducing the evaporation rate and leading to more LSW) in resistant genotypes, so the small amount of LSW cannot be explained in terms of evaporation. If retention is poor, water would accumulate in the base of the whorl. This was not the case so we conclude that the supply of surface water is dominant in determining the amount of LSW and that supply is probably different between genotypes. This conclusion has direct relevance to our observation on the contribution of wax structure in wettness of the central whorl leaf. The supply of LSW forms the basis of another study which will be reported elsewhere.

Table 1. Relationships between central whorl leaf characteristics of sorghum and damage caused by the shoot fly Atherigona soccata

$\begin{array}{llcll}\text { Genotypes } & \begin{array}{c}\text { Resistance } \\ \text { rating' }\end{array} & \begin{array}{c}\text { LSW } \\ \text { score }^{2}\end{array} & \begin{array}{c}\text { Surface } \\ \text { wax } \\ \text { structure }\end{array} & \text { Wett } \\ \text { IS } 18551 & \text { Resistant } & 1.4 & \text { Amorphous } & \text { Low } \\ \text { IS } 2146 & \text { Resistant } & 1.2 & \text { Amorphous } & \text { Low } \\ \text { IS } 1057 & \text { Resistant } & 1.8 & \text { Amorphous } & \text { Low } \\ \text { IS } 1054 & \text { Moderately } & 2.3 & \text { Amorphous } & \text { Low } \\ & \text { Resistant } & & & \text { High } \\ \text { IS } 1046 & \text { Susceptible } & 4.4 & \text { Granular } & \text { High } \\ \text { CSH 1 } & \text { Susceptible } & 4.8 & \text { Crystalline } & \text { High } \\ \text { CSH 5 } & \text { Susceptible } & 4.5 & \text { Crystalline } & \text { Heste }\end{array}$

'Based on damage (deadheart) scores on a 1-9 scale where $1-3=$ resistant, $4 \& 5=$ moderately resistant, $6 \& 7=$ moderately susceptible and $7-9=$ susceptible.

${ }^{2} \mathrm{LSW}$ (leaf surface wetness) means for August; based on a visual score scale of 1-5 where, 1 = no apparent moisture, $5=$ dense droplets.

${ }^{3}$ Based on artificial wetting. 
These results relate closely to our earlier studies which relate LSW to resistance/susceptibility of sorghum to shoot fly. Current and earlier findings (Table 1). lead to the conclusion that there is a link between wax structure. leaf wetness and resistance to shoot fly. Resistant genotypes possess smooth amorphous wax surfaces. have low LSW and do not wet easily. On the other hand, susceptible genotypes possess dense crystals, have high LSW and wet easily.

The major implication of our results is that. since wax structure is under genetic control. although modified by the environment and crop age (Baker. 1982), there may be a link between the genetic potential for the supply of LSW and wax morphology. It is possible to speculate that shoot fly-resistant genotypes are characterised by low supply rates and large contact angles while susceptible genotypes possess high supply rates and smaller contact angles (more wettable surfaces). Since survival of larvac, and their speed of movement and time of arrival at the growing point (and therefore, seedling deadheart) have been shown to be directly related to the degree of wetness of the central whorl leaf, studies on the supply of LSW and the genetics of inheritance of wax morphology will greatly enhance our efforts in breeding for resistance to the sorghum shoot fly.

\section{Acknowledgements}

This paper was submitted as JA No. 1246 by the International Crops Research Institute for the Semi-Arid Tropics (ICRISAT). Some studies were part of the Ph.D. Thesis of P. S. Sree, submitted to Andhra Pradesh Agricultural University.

We appreciate the assistance of Mr A. K. Murthi for initial SEM studies at ICRISAT, and $\mathrm{Mr} \mathrm{R}$. F. Hughes (glasshouse manager, LARS).

\section{References}

Atkin, D. S. J. \& Hamilton, R. J. (1982). Surface of Sorghum bicolour. In The Plant (uticle, pp. 231236. Eds D. F. Cutler. K. L. Alvin and (. E. Price. London: Academic Press.

Baker, E. A. (1982). Chemistry and morphology of plant epicuticular waxes. In The Plant (uticle. pp. 139-165. Eds D. F. Cutler, K. L. Alvin and C. E. Price. London: Academic Press.

Bengston, C., Larsson, S. \& Lilijenberg, C. (1978). Effects of water stress on cuticular transpiration rate and amount and composition of epicuticular wax in seedlings of six oat varieties. Physiologia Plantarum 44. 319-324.

Bianchi, G., Avato, P., Bertirelli, P. \& Mariani, M. (1978). Epicuticular waxes of two sorghum varieties. Phytochemistry 17, 999-10()1.

Blaker, T. W. \& Greyson, R. I. (1988). Developmental variation of leaf surface wax of maize, Zea mays. Canadian Journal of Botany 66, 839-846.

Blum, A. (1963). The penetration and development of the sorghum shootfly in susceptible sorghum plants (in Hebrew). Hassadeh 44, 23-25.

Blum, A. (1975). Effect of the B.M. gene on epicuticular wax deposition and the spectral characteristics of sorghum leaves. Society for the Advancement of Breeding in Asia and Oceania Journal 7(1), 4552.

Fernandes, A. M. S. S. (1965). Studies on plant cuticle VIII. Surface waxes in relation to waterrepellency. Annals of Applied Biology 56, 297-304.

Foboya, O. O. P., Okogun, J. I. \& Goddard, D. R. (1980). Dependence of the hydrocarbon constituents of the leaf waxes of khaya species on leaf age. Phytochemistry 19. 1226-1227.

Fogg, G. E. (1947). Quantitative studies on wetting of leaves by water. Proceedings of the Royal Society of London Series B 134, 503-522. 
Hallam, N. D. (1970). Leaf wax fine structure and ontogeny in Eucalyptus demonstrated by means of a specialized fixation technique. Journal of Microscopy 92, 1.37-144.

Hallam, N. D. (1982). Fine structure of the leaf cuticle and the origin of leaf waxes. In The Plant Cuticle, pp. 197-214. Eds D. F. Cutler. K. L. Alvin and C. E. Price. London: Academic Press.

Holloway, P. J. (1969). The effects of superficial wax on leaf wettability. Annals of Applied Biology 63, $145-153$.

Holloway, P. J. (1970). Surface factors affecting wetting of leaves. Pesticide Science 1. 156-16.3.

Linskens, H. F.'(1951). Quantitativ Bestimmung der Benetzbareit von Blattoberflächen. Planta 38. 591-60).

Mueller, E. L., Carr, P. H. \& Loomis, W. E. (1954). The submicroscopic structure of plant surfaces. American Journal of Botany 41, 59.3-6()).

Nwanze, K. F., Reddy, Y. V. R. \& Soman, P. (1990)). The role of leat surface wetness in larval behaviour of the sorghum shoot fly. Atherigona soccata. Entomologia experimentalis et applicata 56, 187-195.

Nwanze, K. F., Sree, P. S., Butler, D. R., Reddy, Y. V. R. \& Soman, P. (1992). The dynamics of leaf surface wetness of sorghum seedlings in relation to resistance to the shoot fly, detherigona soccata. Entomologia experimentalis et applicata (In press).

Raina, A. K. (1981). Movement, feeding behaviour and growth of larvac of the sorghum shoot fly Atherigona soccata. Insect Science and its Application 2.77-81.

Schieferstein, R. H. \& Loomis, W. E. (1956). Wax deposits on leaf surfaces. Plant Physiology 31. $24(1) 247$.

Sree, P. S. (1991). Factors associated with resistance in sorghum to shoot fly Atherigona soccata Rondani. Ph.D. Thesis, Andhra Pradesh Agricultural University, Rajendranagar, Hyderabad. India. $144 \mathrm{pp}$.

Taneja, S. L. \& Woodhead, S. (1989). Mechanisms of stem borer resistance in sorghum. In International Workshop on Sorghum Stem Borers held at ICRISAT, 17-20 Nolember, 1987, Pp. 1.37 14.3. I Els S. Kearl and V. Sadhana. Patancheru, Andhra Pradesh 502 324, India: IC RISAT.

Tulloch, A. P. \& Bergter, L. (1980). Epicuticular waxes of Echinochloo (rusgalli. Phytochemistry 19, $145-146$.

Tulloch, A. P. \& Hoffman, L. L. (1979). Fpicuticular waxes of Andropogon hallii and A. scoparius. Phytoche'mistry 18, 267-271.

(Received 5 September 199/) 